\title{
ESPESSURA E DENSIDADE DE CÉLULAS ENDOTELIAIS CORNEANAS EM OVINOS
}

\section{(Thickness and density of corneal endothelial cells in ovines)}

\author{
BRANDÃO, C.V.S. ${ }^{1}$; RANZANI, J.J.T.'; RODRIGUES, G.N. ${ }^{2}$; MARINHO, L.F.L.P. ${ }^{2}$; PEIXOTO, T.P. ${ }^{2}$; \\ CREMONINI, D.N. ${ }^{2}$; LIMA, L.S.A. ${ }^{2}$; CHIURCIU, J.L.V. ${ }^{2}$; TEIXEIRA, C.R. ${ }^{3}$ \\ 'Professor Assistente Doutor - Departamento de Cirurgia e Anestesiologia Veterinárias - FMVZ - Unesp - \\ Botucatu; \\ ${ }^{2}$ Pós-graduandos em Medicina Veterinária - área de Cirurgia - FMVZ - Unesp - Botucatu; \\ ${ }^{3}$ Professor Assistente - Departamento de Cirurgia e Anestesiologia Veterinárias - FMVZ - Unesp - \\ Botucatu.
}

\begin{abstract}
RESUMO: A córnea é transparente, sendo suas principais funções a transmissão e a refração da luz. Compreende quatro camadas, dentre elas, o endotélio corneano, que é constituído por uma única camada de células hexagonais interligadas, formando uma barreira entre o estroma corneano e o humor aquoso, limitando a entrada de água e solutos oriundos da câmara anterior para o estroma. Portanto, uma densidade mínima é necessária para manter a transparência e a funcionalidade corneanas. Objetivou-se determinar a densidade de células endoteliais e a espessura corneanas, utilizando-se microscopia especular de não contato, em 22 olhos provenientes de 11 ovinos. A média de densidade celular endotelial corneana foi de 2726 céls $/ \mathrm{mm}^{2}$ e a espessura $654 \mu \mathrm{m}$. Os machos apresentaram médias de densidades superiores e áreas celulares inferiores em relação às fêmeas.
\end{abstract}

Palavras-chave: Córnea, ovino, microscopia especular, densidade celular, espessura.

\begin{abstract}
The cornea is transparent layer of the eye, transmission and refraction of light being their main functions. The endothelium, one of the cornea four layers, is a hexagonal unicellular layer that forms a barrier between the stroma and aqueous humor, obstructing the entrance of water and others solutes from the anterior chamber towards the stroma. In the regard to it, a minimum density of these cells is necessary to maintain the performance and clarity of the eye visual capacity. The main objective of the present research was the determination of the density of endothelial cells and their corneal thickness, using a noncontact specular microscope, in 22 eyes from 11 ovines. The average density of the endothelial corneal was 2726 cels $/ \mathrm{mm}^{2}$ and the thickness $654 \mu \mathrm{m}$. The males displayed a higher average density and a smaller cell area than the females.
\end{abstract}

Key-words: Cornea, ovine, specular microscopy, cellular density, thickness.

\section{Introdução}

A córnea é a única porção transparente da túnica fibrosa do bulbo ocular, sendo suas principais funções a transmissão e refração da luz. Compreende quatro camadas denominadas epitélio, estroma, membrana de Descemet e endotélio (SLATTER, 2005).

O endotélio corneano é constituído por uma única camada de células hexagonais interligadas, formando uma barreira entre o estroma corneano e o humor aquoso (GELATT, 2003). As células endoteliais limitam a entrada de água e de solutos oriundos da câmara anterior para o estroma corneano; portanto, uma densidade mínima destas é necessária para manter a transparência e a funcionalidade corneanas (ANDREW et al., 2001).

O desequilíbrio na disposição ou densidade dessa camada pode ocasionar distúrbios na transparência da córnea; diferentes processos patológicos ou mecânicos podem lesar o endotélio. O edema corneano resulta em uma elevação da espessura e diminuição na transparência, bem como redução dos glicosaminoglicanos estromais, desorganização das lamelas de colágeno e entrada de água (SLATTER, 2005).

A densidade das células endoteliais corneanas já foi descrita em humanos (LANGSTON, 2001; NISHIDA, 2003), cães (GWIN et al., 1982), Ihamas, alpacas (ANDREW et al., 2002) e camelos (AHMED e KARCIOGLU, 1997), bem como suas mudanças em função da idade e condições patológicas que afetam a densidade celular em humanos (GREINER e KENYON, 1994; YAMANE, 2003; SANCHIS-GIMENO et al., 2005) e cães (GWIN et al., 1982).

$\mathrm{Na}$ literatura consultada, não foram verificados estudos ou relatos de densidade celular em ovinos. Sabe-se, que o aumento da espessura e edema corneanos é diretamente proporcional à diminuição da densidade celular endotelial e que alguns fatores como idade e sexo, contribuem para o desenvolvimento das enfermidades (WU et al., 2004).

Correpondencia para:Claudia Valéria Seullner Brandão - Departamento de Cirurgia e Anestesiologia Veterinárias - Faculdade de Medicina Veterinária e Zootecnia da UNESP - Distrito de Rubião Júnior s/n - 18618-000 - Botucatu-SP E-mail:valeriasb@fmvz.unesp.br. 
Em decorrência dos aspectos acima descritos, o escopo deste estudo foi determinar a densidade das células do endotélio além da espessura da córnea em olhos de ovinos recém eutanasiados.

\section{Material e Método}

Foram utilizados 22 olhos normais, provenientes de 11 ovinos mestiços da raça lle de France, com um ano de idade, sendo seis fêmeas e cinco machos. Todos foram submetidos a exame oftalmológico para a exclusão de animais com alterações oculares.

A densidade celular endotelial e a espessura central corneana foram aferidas nos olhos dos ovinos recém abatidos, destinados ao consumo humano, utilizandose microscópio especular de não contato, calibrado e regulado de modo automático (VAN-SCHAICK et al., 2005). Os olhos dos animais foram mantidos a uma distância de aproximadamente $25 \mathrm{~mm}$ do aparelho, sendo realizadas duas fotografias em cada olho com áreas medindo 0,2 x 0,5 mm. A análise microscópica especular inclui área celular mínima, máxima, bem como sua média, além da densidade celular (céls $\left./ \mathrm{mm}^{2}\right)$; para isso avaliou-se um total de 100 células por olho.

$\mathrm{Na}$ análise estatística, a comparação entre os olhos direito e esquerdo para a densidade celular e paquimetria, bem como entre os machos e as fêmeas foram realizadas pelo teste t de Student, com $5 \%$ de significância.

\section{Resultados}

A espessura corneana (média \pm SEM), área celular média e densidade celular corneana estão descritas na TABELA 1, na qual não foram verificadas diferenças estatísticas significantes entre os dois olhos. Já em função do sexo (TABELA 2), apenas a espessura não apresentou diferença significante, sendo verificada uma área celular média maior nas fêmeas e uma densidade celular menor quando comparadas aos machos.

TABELA 1 - VALORES MÉDIOS DA ESPESSURA CORNEANA, ÁREA CELULAR MÉDIA E DENSIDADE CELULAR, NOS OLHOS DIREITO E ESQUERDO DE OVINOS. BOTUCATU, MARÇO/2004. ( $\mathrm{N}=22)$.

\begin{tabular}{lcc}
\hline \multicolumn{1}{c}{ MEDIA \pm SEM } & \multicolumn{1}{c}{ OLHO DIREITO } & OLHO ESQUERDO \\
\hline ESPESSURA $(\mu \mathrm{M})$ & $654.24 \pm 13,15 \mathrm{~A}$ & $653.94 \pm 11,08 \mathrm{~A}$ \\
ÁREA CÉLULAS $\left(\mu \mathrm{M}^{2}\right)$ & $380.48 \pm 17.13 \mathrm{~A}$ & $366.39 \pm 10.37 \mathrm{~A}$ \\
DENSIDADE CELULAR $\left(\mathrm{CÉL} / \mathrm{MM}^{2}\right)$ & $2697.1 \pm 93.38 \mathrm{~A}$ & $2754.8 \pm 77.25 \mathrm{~A}$ \\
\hline
\end{tabular}

TABELA 2 - VALORES MÉDIOS DA ESPESSURA CORNEANA, ÁREA CELULAR MÉDIA E DENSIDADE CELULAR, NAS FÊMEAS E NOS MACHOS DE OVINOS. BOTUCATU, MARÇO/2004. $(\mathrm{N}=22)$.

\begin{tabular}{lll}
\hline \multicolumn{1}{c}{ MEDIA \pm SEM } & \multicolumn{1}{c}{ FÊMEA } & \multicolumn{1}{c}{ MACHO } \\
\hline ESPESSURA $(\mu \mathrm{M})$ & $639.18 \pm 7.46 \mathrm{~A}$ & $671.98 \pm 14.65 \mathrm{~A}$ \\
ÁREA CÉLULAS $\left(\mu \mathrm{M}^{2}\right)$ & $392.15 \pm 15.74 \mathrm{~A}$ & $350.98 \pm 6.00 \mathrm{~B}$ \\
DENSIDADE CELULAR $\left(\mathrm{CEL} / \mathrm{MM}^{2}\right)$ & $2607.1 \pm 87.30 \mathrm{~A}$ & $2868.5 \pm 53.23 \mathrm{~B}$
\end{tabular}

* Teste t pareado; médias seguidas de pelo menos uma letra igual indicam diferenças não significativas $(p<0.05)$.

\section{Discussão}

O endotélio corneano desempenha importante papel na manutenção da transparência da córnea; o uso do microscópio especular permite determinar a densidade de células endoteliais. O conhecimento dos valores normais em ovinos contribuirá com tratamentos clínicos e cirúrgicos, principalmente os procedimentos intra-oculares, assim como nos prognósticos dos mesmos.

No presente estudo, observou-se uma densidade celular endotelial média em ovinos de 2726 cels $/ \mathrm{mm}^{2}$. Esses valores são semelhantes aos descritos na literatura com relação à densidade endotelial de lhamas (ANDREW et al., 2002), nas quais, em média observou-se 2669 céls $/ \mathrm{mm}^{2}$. Já em cavalos (ANDREW et al., 2001), o valor descrito é de 3155 céls $/ \mathrm{mm}^{2}$, enquanto que em cães (GWIN et al., 1982) e alpacas (ANDREW et al., 2002), entre 2300 a 2500 céls $/ \mathrm{mm}^{2}$. Nos humanos adultos (BOVELLE et al., 1999), a média é de 3000 céls $/ \mathrm{mm}^{2}$.

Uma menor densidade e maior área celular média, estatisticamente significantes, foram verificadas nas fêmeas em relação aos machos. Andrew et al. (2001) relataram comportamento semelhante no seu estudo em eqüinos. A espessura corneana em ovinos, ao redor de 654 $\mu \mathrm{m}$, demonstrou valor inferior ao relatado em eqüinos (ANDREW et al., 2001), representado por $893 \mu \mathrm{m}$. 


\section{Conclusões}

A densidade celular média e a espessura corneana em ovinos de um ano de idade são de 2726 cels $/ \mathrm{mm}^{2} \mathrm{e}$ $654 \mu \mathrm{m}$ respectivamente. Os machos apresentam médias de densidades superiores e áreas celulares inferiores, quando comparados às fêmeas.

\section{Referências}

AHMED, W.S.; KARCIOGLU, Z.A. Comparative morphology of camel and human. corneas. Veterinary and Comparative Ophthalmology, v.7, n.4, p.226-232, 1997.

ANDREW, S.E.; WILLIS, A.M.; ANDERSON, D.E. Density of corneal endothelial cells and corneal thickness in eyes of euthanatized horses. American Journal of Veterinary Research, v.62, n.4, 2001.

ANDREW, S.E.; WILLIS, A.M.; ANDERSON, D.E. Density of corneal endothelial cells, corneal thickness, and corneal diameters in normal eyes of llamas and alpacas. American Journal of Veterinary Research, v.63, n.3, p. 326-329, 2002.

BOVELLE, R.; KAUFMAN, S.C.; THOMPSON, H.W. Corneal thickness measurements with the Topcon SP2000P specular microscope and an ultrasound pachymeter. Archives Ophthalmology, v. 117, p.868-870, 1999.

GELATT, K. N. Manual de oftalmologia veterinária. Barueri: Editora Manole Ltda, 2003. 594p.

GREINER, J. V.; KENYON, K.R. Corneal aging. In: ALBERT, D.M.; JAKOBIEL, F.A., eds. Principles and practice of ophthalmology. Basic Sciences. Philadelphia: WB Saunders Co, 1994. p.689-696.
GWIN, R.M.; LERNER, I.; WARREN, J.K. Decrease in canine corneal endothelial cell density and increase in corneal thickness as functions of age. Investigative Ophthalmology Visual Science, v. 22, p.267-271, 1982.

LANGSTON, D.P. Tecnicas de Exame Oftalmológico e Testes Diagnósticos. In: LANGSTON, D.P. Manual de Oftalmologia: Diagnóstico e Tratamento. 4 ed. Rio de Janeiro: Médica e Cientifica, 2001, p. 1-42.

NISHIDA, T. Comparison of confocal biomicroscopy and noncontact specular microscopy for evaluation of the corneal endothelium. CORNEA. v.22, n.6, p.512-516, 2003.

SANCHIS-GIMENO, J.A.; LLEO-PEREZ, A.; ALONSO, L.; RAHHAL, M.S.; MARTINEZ-SORIANO. Corneal endothelial cell density decreases with age in emmetropic eyes. Histololgy and Histopathology, v. 20, n. 2, p. 423-427, 2005.

SLATTER, D. Fundamentos de Oftalmologia Veterinária. 3.ed. São Paulo: Roca. 2005. 686p.

WU, Q.; DUAN, X.; JIANG, Y.; QING, G.; JIANG, B.; SHI, J. Normal value of the central corneal thickness measured by non-contact specular microscope. Yan Ke Xue Bao, v. 20, n.4, p. 229-232, 2004.

VAN-SCHAICK, W.; VAN DOOREN, B.T.; MULDER, P.G.; VOLKER-DIEBEN, H.J. Validity of endothelial cell analysis methods and recommendations for calibration in Topcon SP-2000P specular microscopy. Cornea. v.24, n.5, p.538-544, 2005.

YAMANE, R. Curvatura, paquimetria e microscopia especular da córnea. In: YAMANE, R. Semiologia Ocular. 1 ed. Rio de Janeiro: Cultura Médica, 2003, p.89-102.

Recebido para publicação:

$30 / 11 / 2005$

Aprovado:

$27 / 05 / 2006$ 